\title{
Contribución para la autonomía en el aprendizaje del portugués como lengua de "acogimiento": la historia de una mujer inmigrante venezolana
}

\section{Rosana Daza de Garcia* \\ Resumen}

Este articulo tiene como objetivo resignificar la comprensión acerca de lengua de "acogimiento" al relatar mi experiencia como mujer inmigrante venezolana y aprendiz de la lengua portuguesa en Brasil, basándome en teóricos como Monte Mór (2014), Pennycook (2007), entre otros. Dialogo sobre algunas estrategias aplicadas durante el proceso de mi adaptación al nuevo país, en el cual pude desarrollar autonomía y diversas capacidades para aprender una lengua adicional/extranjera como la portuguesa. Reflexiono, incluso, sobre aspectos como cultura, identidad y algunas estrategias de estudio que pueden ser utilizados de forma autodidacta en la cotidianidad de un inmigrante para la construcción de sentidos. Como resultado, resalto que la construcción de sentido, sin depender totalmente de instrucción formal, puede ampliar investigaciones y formación ciudadana continuada acerca de lengua de "acogimiento", a partir de la iniciativa de socialización y creatividad por parte del inmigrante en el país en el que paso a residir. De esa manera, espero contribuir con esta relevante temática sobre los estudios lingüísticos aplicados en contextos migratorios (resignificando el concepto de lengua de "acogimiento").

Palabras-clave: Lengua portuguesa de "acogimiento". Contextos migratorios. Autonomía. Letramento crítico. Translinguagem.

* Universidade Federal de Mato Grosso do Sul (UFMS). Mestre em Letras pela Universidade Federal da Grande Dourados (UFGD). Doutoranda em Estudos da Linguagem na Universidade Federal de Mato Grosso do Sul (UFMS) em Campo Grande e professora substituta da mesma Universidade em Aquidauana. ORCID: https://orcid.org/0000-0002-4314-953X. 


\section{Contribuições para a autonomia no aprendizado de português como língua de acolhimento: a história de uma mulher imigrante venezuelana}

\section{Resumo}

Este artigo tem como objetivo tentar ressignificar a compreensão acerca de língua de acolhimento ao relatar minha experiência como imigrante venezuelana e aprendiz de língua portuguesa no Brasil, a partir de teóricos como Monte Mór (2014), Pennycook (2007), entre outros. Dialogo com algumas estratégias usadas durante o processo da minha adaptação no novo país, no qual pude desenvolver autonomia e diversas capacidades para aprender uma língua adicional/ estrangeira como o português. Reflito sobre aspectos como cultura, identidade e algumas estratégias de estudo que podem ser utilizadas de forma autodidata na vida cotidiana de um imigrante para a construção de sentidos. Como resultado, ressalto que a construção de sentido sem depender totalmente de instrução formal pode ampliar pesquisas e formação cidadã continuada acerca de língua de acolhimento, a partir da iniciativa de socialização e criatividade por parte do imigrante no país em que passou a residir. Dessa forma, espero contribuir para esse tema relevante aos estudos linguísticos aplicados em contextos migratórios.

Palavras-chave: Língua portuguesa de acolhimento. Contextos migratórios. Autonomia. Letramento crítico. Translinguagem

Recebido em: 08/03/2021 // Aceito em: 30/03/2021. 


\section{Introducción}

Aproximadamente en el año 2019, después de un año desde que "la operación acogida del ejército brasileño" decidió embarcar inmigrantes venezolanos con destino a varios estados de Brasil, Dourados, en Mato Grosso del Sur, se convirtió en la "[...] segunda ciudad brasileña en número de inmigrantes acogidos, principalmente, venezolanos."1 (NUNES, 2019a, p. 19). Diferentes organismos públicos, iglesias, escuelas y universidades empezaron a brindar apoyo y a buscar diferentes formas de organizarse para la recepción de esas personas.

Entre esas acciones de apoyo, se ofrecieron clases gratuitas para la enseñanza de la lengua portuguesa por

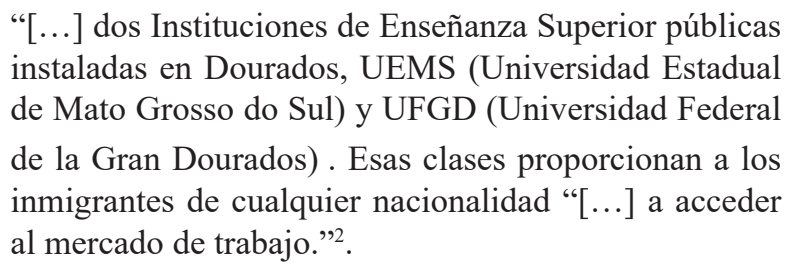

Contando con el apoyo de "[...] pessoas ligadas à UFGD, UEMS e também voluntários sem vínculo institucional [...]”, observándose que "[...] a dificuldade de falar e ser compreendido é a maior dor para quem só quer poder se integrar a uma nova realidade [...]"44 (ARAÚJO, 2019, p. 1). Voy a narrar mi experiencia como mujer aprendiz de la lengua portuguesa y voy a mostrar como a través de mis actividades cotidianas, conseguí

\footnotetext{
1 NUNES, Cristina. Venezuelanos colocam Dourados em destaque no ranking de imigrantes. O progresso, Dourados, n. 84, ed. especial, p. 19, 19/20 dez. 2019a. Disponível em: https://issuu.com/progresso/docs/13607. Acesso em: 03 fev. 2020.

2 En el original: "[...] a terem acesso ao mercado de trabalho." Traducción nuestra.

3 En el original: “[ ...] pessoas ligadas à UFGD, UEMS e também voluntários sem vínculo institucional [...]”. Traducción nuestra.

4 En el original: “[...] a dificuldade de falar e ser compreendido é a maior dor para quem só quer poder se integrar a uma nova realidade [...]".Traducción nuestra.
} 
Contribución para la autonomía en el aprendizaje del portugués como lengua de "acogimiento": la historia de una mujer inmigrante venezolana

integrarme a mi nuevo país, utilizando estrategias de aprendizaje de manera autónoma. De esa forma, entiendo que expandí el concepto de lengua de "acogimiento".

\section{La identidad en la inmigración venezolana}

Actualmente, a nivel mundial, el movimiento migratorio venezolano ha causado fuertes impactos sociales, económicos y culturales, tanto en los países que reciben a los refugiados como a las personas que solicitan refugio.

Entre algunas dificultades que específicamente las mujeres enfrentan actualmente, están los asuntos relacionados con la documentación, su permanencia legal en el país y la necesidad de empleo. Este asunto podría intensificarse si existen algunas limitaciones lingüísticas por ser la lengua del país de acogida distinta a la que la inmigrante práctica.

Según la Organización Internacional para las Migraciones (OIM)/Ministerio de Desarrollo Social del Gobierno de la Ciudad Autónoma de Buenos Aires, existen diferentes tipos de violencia que las mujeres inmigrantes experimentan durante el proceso de salida del país:

[...] viajar solas es peligroso para las mujeres migrantes y refugiadas de Venezuela y lo que explica en parte por qué hay más hombres que mujeres viajando solos. Por otra parte, la precariedad económica, expresada en las dificultades reseñadas, y la abrumadora carga de tareas de cuidado de las mujeres migrantes y refugiadas, aumenta exponencialmente su riesgo a sufrir diversos tipos de violencia ${ }^{5}$. (OIM, 2020)

5 https://reliefweb.int/.../files/resources/4-gender-violencia.pdf . 
Ante ese escenario y considerando el objetivo de este artículo, me surge la siguiente pregunta: ¿Como conseguí aprender portugués sin depender de instrucción formal a lo largo de 5 años desde que llegué en Dourados? ¿Qué estrategias de aprendizaje creé/creo y utilicé/utilizo en este proceso?

\section{La autonomía en el aprendizaje de la lengua adicional}

En la búsqueda de dar respuesta a las preguntas anteriores y teniendo en cuenta que, a pesar de aquellas políticas de interiorización del proyecto deEstado, conocidocomo “Operación Acogida", de hecho, comenzó solamente con el traslado de hombres venezolanos. Seguidamente, al pasar del tiempo, se fueron trasladando también mujeres y niños observándose que “[...] cada día más familias llegan a la ciudad, con la esperanza de una vida mejor." (MORANDI, 2020, p. 1). ${ }^{6}$ Hasta el día de hoy, muchos siguen por cuenta propia reagrupándose con su familia en Dourados.

Esa movilización secundaria de las mujeres y población infantil generó algunas situaciones que fueron de más impacto social, fundamentalmente, aquellas relacionadas al dominio de las lenguas, tanto portuguesa, en el caso de los inmigrantes, como la española, por parte de los profesores y funcionarios públicos.

Teniendo como objetivo central de este artículo mostrar la importancia del poder de aprender con autonomía la nueva lengua (portuguesa) en el país de acogida (Brasil), compartiré algunas estrategias que he utilizado y unas reflexiones sobre cómo el lenguaje se encuentra recubierto de una autoridad que

6 En el original: "A cada dia mais famílias chegam à cidade, na esperança de uma vida melhor. O foco é a indústria frigorífica, que não consegue absorver todas as pessoas." Traducción nuestra. 
Contribución para la autonomía en el aprendizaje del portugués como lengua de "acogimiento": la historia de una mujer inmigrante venezolana

surge desde el exterior del individuo. Estando relacionado de forma directa con el lócus de enunciación (BHABHA, 1988), se puede percibir que la complejidad del asunto relacionado al lenguaje parte de la vinculación con un contexto social especifico y a su turno, ideológico. En ese caso, me refiero a la sociedad brasileña, sobre todo reconociéndome como mujer blanca, pedagoga, doctoranda en un Programa de Posgrado en Estudos de Linguagens en una universidad pública; casada con otro inmigrante (cubano, agrónomo); madre de tres hijas con edades comprendidas entre 3 y 8 años.

En un primer momento, voy a problematizar el aprendizaje del portugués como lengua de "acogimiento", abordando, de forma reflexiva, el conocimiento que se adquiere por la propia experiencia del aprendiz y cómo se desarrolla involucrando el contexto y sus interrelaciones entre vecinos y miembros de la comunidad. Al mismo tiempo, busco dialogar con los conceptos teóricos seleccionados.

En ese mismo sentido, se tiene en cuenta que existen diferentes espacios sociales y en cada uno de ellos se ejercen varios tipos de relaciones de poder, inclusive que:

El fenómeno de la globalización ha perpetuado la premisa de que saber inglés puede representar ventajas, como oportunidades y estatus social, dentro de un contexto donde la lengua inglesa ha asumido innegablemente un papel central en la comunicación, negocios e interacción con hablantes de otras lenguas. (MONTE MÓR, 2014, p. 22). ${ }^{7}$

Conforme los apuntamientos de Monte Mór (2014, p. 22), para describir cómo fue mi proceso de aprendizaje, resalto las

7 En el original: "The phenomenon of globalization has perpetuated the premise that knowing English may represent advantages, such asopportunities and social status, within a context where the English languagehas undeniably assumed a central role in communication, business andinteraction with speakers of other languages". 
pocas oportunidades que tuve de utilizar el español, mi lengua de uso, en algunos espacios de poder (instituciones académicas, centros de salud). De esa forma, me vi obligada a solo utilizar la lengua portuguesa $\mathrm{y}$, en muchos momentos, usar el silencio como respuesta por no dominar la lengua del lugar o tener las palabras precisas para expresar las ideas o pensamiento que surgían en mi mente.

Por ejemplo, en el aula, durante la maestría, se permitía a los alumnos que participaran dando a conocer los criterios sobre los temas trabajados. Observé que cuando me tocaba a mí (usando palabras en portugués y en español), el profesor solía a traducir o interpretar en portugués lo que yo había dicho. Sin embargo, mi dificultad no era entender, sino hablar el portugués. Así, me daba cuenta de que lo que el profesor decía no era lo que yo quería transmitir. Luego me preguntaba si era lo que quise decir y mientras pensaba cómo explicarlo de nuevo, otros compañeros (que consideraban tener dominio del español) discutían cuál había sido mi idea. Por fin, prefería callarme y dejar que los otros dijeran que era lo que yo había pensado o entendido.

Como inmigrantes, las resistencias al conocimiento y a las nuevas costumbres, en algunas oportunidades, limitan el proceso de adaptación e integración. Cuando pensamos en el aspecto lingüístico, según Rajagopalan (2008, p. 70), tenemos que "[...] dominar la lengua extranjera, hacer con que ella forme parte de nuestra propia personalidad [...]", 8 eso no significa que ella va a dominarnos o que vamos a tener que olvidar aquella que practicamos diariamente.

En otras palabras, sugiero tener en cuenta, no solo la historia del lugar que acoge, sino, parejamente, reconocer el

$\overline{8}$ En el original: "[...] dominar a língua estrangeira, fazer com que ela se torne parte de nossa própria personalidade [...].”Traducción nuestra. 
Contribución para la autonomía en el aprendizaje del portugués como lengua de "acogimiento": la historia de una mujer inmigrante venezolana

valor de la propia vivencia del inmigrante, permitiendo que fluya la naturaleza dinámica propia del lenguaje y surjan nuevas construcciones de sentidos. Del mismo modo, que se considere la perspectiva sobre el lenguaje que Bakhtin (1999) defiende, la cual avala que el lenguaje siendo dialógico, puede permitir que encontremos varias voces cada vez que se construye un enunciado. De esa manera, existiendo una relación interdiscursiva entre el otro y yo en un momento especifico, torna las prácticas sociales el centro donde los enunciados surgen y la persona se posiciona.

Otro ejemplo fue el proyecto "Dialogando con las artes", con el cual se abrió un espacio para "[...] la lengua española y clases de música para decenas de niños [...]"9 (NUNES, 2019b, p. 1), presentando a los profesores brasileños alternativas de acolhimento para los inmigrantes, principalmente para los que venían de Venezuela el inicio del año 2019. Como profesora de español, observé que se puede construir el conocimiento entendiendo el espacio y tiempo del alumno, que, en ese caso, estando en Brasil, hablaban una lengua (portuguesa) diferente a la que yo practico (español).

Sin embargo, en los cursos de portugués como "acogimiento", observamos que algunos colaboradores, consiguen con mucha sensibilidad, que el conocimiento sea coconstruído entre profesor y alumnos colaborativamente. Lo que quiere decir, que también pueden existir iniciativas con estrategias donde el inmigrante, de forma independiente, pueda aprender la lengua adicional (portugués).

Según Rajagopalan (2003, p. 59), “[...] nunca en la historia de la humanidad la identidad lingüística de las personas estuvo tan sujeta como en los días de hoy a las influencias extranjeras

9 En el original: "[...] a língua espanhola e aulas de música para dezenas de crianças [...]. Traducción nuestra. 
[...]"; ${ }^{10}$ el inmigrante, haciendo uso de su repertorio lingüístico y de sus actividades cotidianas, tiene la capacidad de dominar no solo la lengua del país que lo acogió, sino también, la cultura y sus costumbres, desarrollando habilidades para intercambiar saberes con personas de ese país.

De esta misma manera, Canagarajah (2017, p. 46) afirma que reconocer "[...] las prácticas comunicativas preferidas por los informantes como diferentes de aquellas adoptadas en las políticas e instituciones neoliberales [... ${ }^{\prime \prime 11}$ contribuyen para una revisión (auto)crítica de su propia experiencia de aprendizaje.

Considerando que Dourados es una ciudad fronteriza, las posibilidades de que los habitantes hablen dos o más lenguas son bastante altas, el translinguagem define que:

"Estudiantes bilingües son escritores mejores si tienen autorización para prescribir con todos los recursos de lenguaje que pueden usar. Estudiantes bilingües son mejores pensadores si encorajados a investigar tópicos en cualquier idioma". ${ }^{12}$ (YIP; GARCIA, 2018, p. 170).

Referente a ese punto, hablaré brevemente cómo fue la práctica de la maestría en la Facultad de Letras de la UFGD.

Inicialmente, es importante subrayar que algunos profesores me permitían que entregara mis textos de análisis en español, pero otros no. Cuando se distribuían los textos para exámenes, exposiciones o reseñas, ésos, en su mayoría, estaban escritos en diferentes idiomas (inglés, portugués y español), siendo de más difícil comprensión los de inglés, primeramente, y luego los de portugués.

\footnotetext{
10 En el original: "[...] nunca na história da humanidade a identidade linguística das pessoas esteve tão sujeita como nos dias de hoje às influencias estrangeiras [...].” Traducción nuestra.

11 En el original: "I consider the communicative practices preferred by the informants as different from those adopted in neoliberal policies and institutions.”. Traducción nuestra.

12 En el original: "Estudantes bilíngues são escritores melhores se tiverem autorização para pré-escrever com todos os recursos de linguagem que podem usar. Estudantes bilíngues são melhores pensadores se encorajados a pesquisar tópicos em qualquer idioma." Traducción nuestra.
} 
Contribución para la autonomía en el aprendizaje del portugués como lengua de "acogimiento": la historia de una mujer inmigrante venezolana

Entre los aspectos más relevantes del aprendizaje como estudiante inmigrante, menciono que fui la primera estudiante que realizó su tesis de maestría en una lengua que no era la portuguesa, recibiendo, incluso, reconocimiento por referido asunto de la Cámara Municipal de Dourados. De alguna forma, el hecho de que los profesores me hubiesen permitido el uso de la lengua que practicaba para desarrollar un trabajo de tan grande albergadura, utilizando todos mis recursos del lenguaje y aprendiendo junto con los profesores brasileños sobre teorías del país que me acogió, se hizo una experiencia enriquecedora e inolvidable.

Adaptando las palabras de García (2009, p. 53), las “[...] prácticas sociales, múltiplas e interdependientes que, sin interrupciones, se ajustan al campo multilingüe y multimodal del acto comunicativo [... $]^{\text {"13 }}$ son favorables para el progreso de manera fluida en los alumnos que van comunicándose y dejando aparecer lo que piensan sobre determinado asunto.

Manteniendo el contexto del párrafo anterior, agregaré que, en la mayoría de las casas de los inmigrantes venezolanos, la lengua que se usa es el español y la lengua portuguesa se la utiliza afuera. En algunos casos, donde se encuentran niños o niñas dentro del hogar, existe un ambiente multilingüe. Las lenguas no actúan de forma separada; las palabras fluyen según el repertorio lingüístico que posee el miembro de la familia o simplemente se comunica una idea sin pensar en que lengua se está diciendo.

El translinguagem se lo aplicamos diariamente en mi familia. Durante mi proceso de adaptación, utilicé ambas lenguas (portuguesa y española), sin detenerme a pensar muchas veces,

13 En el original: “[...] práticas sociais, múltiplas e interdependentes, que ininterruptamente se ajustam ao terreno multilíngue e multimodal do ato comunicativo $[. .$.$] ". Traducción nuestra.$ 
cuando usaba una y cuando usaba la otra. Generalmente, me enteraba cuando mi interlocutor me alertaba.

Conforme salienta Wei $(2018$, p. 1), esas “[...] prácticas dinámicas y fluídas que transfieren las fronteras entre lenguas, variedades lingüísticas"14 que pueden transformarnos en ciudadanos autónomos y creativos.

Debo acotar que esas prácticas pueden suceder no solo en una universidad o una escuela, sino, también, dentro de una casa, un supermercado o simplemente en medio de una calle. Eso se debe a que el conocimiento tiene implícito el contexto social. Las convivencias y las diferentes formas de coconstrucción de conocimiento auxilian a nuestro desarrollo de las actividades como inmigrantes.

Cuando yo llegué a Dourados en 2015, no existían cursos de portugués para "acogimiento" y cada inmigrante o refugiado, que llegaba a Brasil, debía buscar de manera particular la forma de aprender la lengua portuguesa; procurar alcanzar el desarrollo de sus competencias por sí mismo: "La venezolana $\mathrm{X}$ busca maneras de adaptarse al nuevo país y a la nueva lengua. Ella cuenta que aprendió el portugués sola, escuchando los douradenses conversando". ${ }^{15}$

A partir de ahora, describo las estrategias que utilicé para aprender el portugués.

La primera estrategia fue fijar la atención a los movimientos corporales de los vecinos (usaban las manos para referirse a que acostumbraban a tomar el tereré y si era costumbre en Venezuela); su manera de mover sus labios cuando pronunciaban algunas

\footnotetext{
14 En el original: "dynamic and fluid practices that transfer the borders between languages, linguistic varieties." (WEI, 2018, p. 1). Traducción nuestra.

15 En el original: "A venezuelana $\mathrm{X}$ tem buscado maneiras de se adaptar ao novo país e à nova língua. Ela conta que aprendeu o português sozinha, ouvindo os douradenses conversando.” Traducción nuestra. (NUNES, 2019, p. 19). Disponível em: https:// issuu.com/progresso/docs/13607. Acesso em: 03 fev. 2020.
} 
Contribución para la autonomía en el aprendizaje del portugués como lengua de "acogimiento": la historia de una mujer inmigrante venezolana

palabras (imigração, comunicação, nacionalização). Además de los sonidos nasales, funcionaba como una regla cambiar el final de las palabras que en español terminan en "ción" en "ção" (portugués). En diversas oportunidades, utilicé frases con las dos lenguas ( $\mathrm{Eu}$ gostaria tener una conversación contigo) utilizándome las manos para señalizar con quien quería hablar.

Siendo el lenguaje verbal una habilidad desarrollada por hombres, mujeres y niños en su diario vivir, no puedo dejar de mencionar que, en mi caso, existían momentos en los cuales ello no sucedía de forma fluida y automática. Después de varios encuentros con brasileños, hubo intercambios de saberes con los vecinos como comparaciones entre algunos significados en español y portugués y la pronuncia en ambas lenguas (portuguesa y española). Para eso, usé imágenes de revistas, fotos en el celular y los movimientos de mi cuerpo. Como mujer, generaba un efecto que, en ocasiones, no resultaba y no me hacía entender, aun con las mismas mujeres.

Esa forma de aprender me lleva a pensar en la analogía que Takaki (2014, p. 25) hace sobre "el lenguaje y el partido de fútbol"16 (y cuestiones de la sociedad). La autora explica que los términos "lengua/lenguaje" pueden ser usados juntos y también separados, debido a que cada una de esas palabras es, de alguna manera, "performativa", ${ }^{17}$ dando sentido a un contexto y a un tiempo determinado de forma dinámica.

Considerando que uno de los propósitos del curso de "acogimiento" de portugués es que pueda "diseminarse en la sociedad un espíritu de solidaridad", ${ }^{18}$ entiendo que será

\footnotetext{
16 En el original: "a linguagem e o jogo de futebol". Traducción nuestra.

17 Una forma de pensar sobre el uso y la identidad del lenguaje entendiendo que los lenguajes y las identidades son remodeladas.

18 En el original: "disseminar-se na sociedade um espírito de solidariedade”. Traducción nuestra. NUNES, Cristina. Venezuelanos colocam Dourados em destaque no ranking de imigrantes. (NUNES, 2019, p. 19). Disponível em: https://issuu.com/progresso/ docs/13607. Acesso em: 03 fev. 2020.
} 
fundamental realizar un análisis crítico que involucra discusiones teóricas para, así, dar respuestas a situaciones específicas en contextos migratorios y la autonomía que como inmigrantes pueden tener.

Por ejemplo, a medida que existe un diálogo entre dos o más personas de lenguas diferentes, los recursos utilizados son siempre diversos y diferentes:

1- ¿Cómo se pueden construir los significados en una determinada situación?

2- ¿Cómo las personas consiguen que sus mensajes sean comprendidos?

3- ¿Cuál es el propósito de este dialogo? ¿expresarse o usar (adecuadamente) la lengua?

4- ¿De quién es el interés por el entendimiento del mensaje? ¿solo de quien habla o de quien escucha?

Esas preguntas nos permiten pensar que, como seres sociales por medio del contacto y de relacionamientos, conseguimos aprender no solo la lengua, sino el uso según los contextos en que se la práctica. Sobre eso, Volóchinov (2018 [1929], p. 177) postula que:

Lo que importa para el hablante es aquel aspecto de la forma lingüística gracias al cual ella puede surgir en un contexto concreto, gracias al cual ella se vuelve una señal adecuada en las condiciones de una situación concreta. (VOLÓCHINOV, 2018 [1929], p. 177). ${ }^{19}$

En ese momento, es importante mencionar que hay entre inmigrantes y no inmigrantes, en la escuela o en la misma casa, diferentes tipos de relacionamiento y que las "complejidades en la enseñanza de lenguas y sus contextos acaban posibilitando

19 En el original: "O que importa para o falante é aquele aspecto da forma linguística graças ao qual ela pode aparecer em um contexto concreto, graças ao qual ela se torna um sinal adequado nas condições de uma situação concreta." Traducción nuestra. 
Contribución para la autonomía en el aprendizaje del portugués como lengua de "acogimiento": la historia de una mujer inmigrante venezolana

formas locales de conocimiento sobre el lenguaje y la enseñanza" (PENNYCOOK, 1989, p. 613). ${ }^{20}$ Enfatizo que el referido autor destaca que haciendo "[...] visibles las maneras por las cuales, todas las prácticas de lenguaje son actos sociales performativos que, aun muchas veces repetitivos, son siempre localizados de forma diferente."21 (PENNYCOOK, 2007, p. 128). La práctica diaria es que me permitió aprender el portugués.

Es por eso que, en este artículo, expongo (mi autonomía, iniciativa y creatividad) las estrategias de aprendizaje de la lengua portuguesa de manera autónoma y asumo el status de autoraperformadora (PENNYCOOK, 2010). Describo las diferentes experiencias que, durante el proceso de aprendizaje de la lengua portuguesa, me permitieron probar que las prácticas de lenguaje en la cotidianidad hacen posible el dominio de cualquier lengua adicional sin necesidad de dejar de practicar otra.

Abordando la visión de Pennycook (1989), "El lenguaje y la enseñanza de lenguas están siempre inscrita en relaciones de poder y son, por lo tanto, asuntos políticos" (PENNYCOOK, 1989, p. 594). ${ }^{22}$ Para el autor, ese pensamiento tiene mucha influencia en los proyectos educativos, observándose el dominio en espacios de fuerza social, económica y política.

La segunda estrategia se basa en el uso de internet que fue esencial para aprender nuevas palabras; conocer sus diferentes tipos de acento y los diversos usos que, al igual que el español dependen del contexto. Procuré periódicos con noticias sociales; escuchaba, inicialmente, música brasileña con leyenda en español. Tras eso, escribía la letra de la canción para cantarla mientras la

\footnotetext{
20 En el original: "We need to recognize the complexities of language teaching and its contexts, and strive to validate other, local forms of knowledge about language and teaching." Traducción nuestra.

21 En el original: "visible ways in which all language practices are performative social acts that, even often repetitively, are always located differently."

22 En el original: "The way in which language and language teaching are always inscribed in relations of power and are therefore political issues.”. Traducción nuestra.
} 
escucha sonar; ver películas o telenovelas en portugués cuando tenía que prestar mucha atención a los movimientos corporales. Las variedades lingüísticas variaban por la clase social del personaje, y eso me permitió que percibiera las diferencias entre la lengua formal y la informal.

De esa misma manera, las imágenes de las propagandas me enseñaban los nombres de los productos y objetos necesarios para mi consumo dentro de casa, entre ellos: utensilios de limpieza, alimentos, ropas. Con la propaganda de productos de limpieza (champú) aprendí que en portugués se dice "cabelo" y no "cabello"; identifiqué que, generalmente, las palabras como "fuerte" o "juego" eran en portugués "forte" o "jogo"; la imagen del champú me hacia recordar la pronunciación de la palabra.

Para poder adquirir esos conocimientos, debo reconocer que es importante tener un poco de creatividad y aceptar que, aprender por nuestra propia cuenta, requiere disciplina y mucha dedicación. Al mismo tiempo, se tiene la oportunidad de construir "nuevos" significados asumiendo sus problematizaciones.

Sobre el uso de las tecnologías, Castells (2000) postula que "[...] la sociedad [actual] no puede ser entendida ou representada sin sus instrumentos tecnológicos." (CASTELLS, 2000, p. 5). ${ }^{23}$ Corroborando ese posicionamiento, Lankshear e Knobel (2007, p. 1) introducen los "letramentos" en una perspectiva plural y ubicada, señalando que

Comprender los letramentos desde una perspectiva sociocultural significa que leer yescribir solo pueden ser entendidos en contextos sociales, culturales, políticos, económicos, y de prácticas históricas para los cuales son partes integrantes. (LANKSHEAR; KNOBEL, 2007, p. 1). ${ }^{24}$

\footnotetext{
23 En el original: "a sociedade [atual] não pode ser entendida ou representada sem seus instrumentos tecnológicos". Traducción nuestra.

24 En el original: "Understanding literacies from a sociocultural perspective means that reading and writing can only be understood in the contexts of social, cultural, political, economic, historical practices to which they are integral, of which they are a part.”.Traducción nuestra.
} 
Contribución para la autonomía en el aprendizaje del portugués como lengua de "acogimiento": la historia de una mujer inmigrante venezolana

Los contextos conllevan Discursos (GEE apud LANKSHEAR; KNOBEL, 2007) que son:

Modos socialmente reconocidos de usarse el lenguaje (lectura, escrita, habla, escucha), gestos y otras semioses (imágenes, sonidos gráficos, signos, códigos, modos de pensar, creer, sentir, valorizar, actuar/hacer y relacionarse con personas y cosas, de forma que podemos identificarnos y reconocernos como miembros de un grupo socialmente significativo, o participando con papel relevante. (GEE apud LANKSHEAR; KNOBEL, 2007, p. 3). ${ }^{25}$

Fue de esa manera, como señalé anteriormente, que conseguí participar y relacionarme con personas en Brasil que me identificaban o me reconocían como mujer venezolana en diferentes espacios (académicos, laborales, entre otros).

Eso permite pensar en espacios donde:

[...] las personas leen y escriben diferentemente de diferentes prácticas sociales, esas diferentes formas con las palabras hacen parte de diferentes maneras de ser personas con diferentes facetas de hacer la vida. (LANKSHEAR; KNOBEL, 2006, p. 13). ${ }^{26}$

Entendiendo lo que la citación anterior plantea, resaltaré que, cuando el inmigrante muestra que él tiene una lengua diferente; que su cultura o costumbre es distinta a la de cualquier persona que no sea inmigrante, el aspecto que se debe valorar es el de que se trata de una persona con una seria de experiencias o pensamientos llenos de su lugar de origen. Tal vez, se podría definir ese proceso como el inicial, en cualquier contexto

\footnotetext{
25 En el original: "Discourses are socially recognized ways of using language (reading, writing, speaking, listening), gestures and other semiotics (images, sounds, graphics, signs, codes), as well as ways of thinking, believing, feeling, valuing, acting/doing and interacting in relation to people and things, such that we can be identified and recognized as being a member of a socially meaningful group, or as playing a socially meaningful role." Traducción nuestra.

26 En el original: "People read and write differently out of different social practices, and these different ways with words are part of different ways of being persons and different ways and facets of doing life." Traducción nuestra.
} 
migratorio, donde la persona en contactos con otros diferentes, asume desafíos, unos más grandes que otros para integrarse a una actividad social, bien sea de estudio o de trabajo.

Además de eso, es esencial que estemos en constante contacto con las personas de nuestra localidad para estar siempre actualizados con las situaciones que suceden en ese lugar y en todo el país. Para que eso pueda suceder, se necesita conocer a los vecinos; salir a caminar y mantener una actitud motivadora. Como amas de casa, nuestro tiempo está limitado por los niños, los quehaceres del hogar. Sin embargo, podemos llevar a los niños al parque y aprovechar para charlar con las personas que allí están; podemos hacer una comida típica de nuestro país y compartirlo con algún vecino; hacerle saber la necesidad de conocer los centros de salud cerca, panaderías o farmacias, De esa forma, generaremos temas para desarrollarlos de manera más profunda próximamente.

Tenemos conciencia de que "[...] generalmente los procesos selectivos, vestibulares, dentre otros, en Brasil, consideran los extranjeros, pero no los inmigrantes o refugiados" (O Progresso/ El Progreso, 2019), ${ }^{27}$ pues algunos documentos solicitados (título revalidado, estar naturalizado) necesitan ser tramitados por proceso que requieren, en su mayoría, que el inmigrante, sea cual sea su nacionalidad, tenga ya una estabilidad económica para poder adquirirlo. Conocer cómo funcionan esos procesos le exige al aprendiz un sumo interés por explorar cada una de las estrategias que le facilitarán alcanzar su objetivo, sea este laboral o académico.

Es por eso por lo que, en mi caso, aun en aquel momento cuando requería administrar y organizar el uso de mi tiempo

$\overline{27}$ Disponible en: O Progresso, Edição especial, p. 19, publicado el 19/20.12.2019. 
Contribución para la autonomía en el aprendizaje del portugués como lengua de "acogimiento": la historia de una mujer inmigrante venezolana

entre las actividades como ama de casa, académicas y laborales, decidí participar de varios procesos selectivos tanto para estudio como para trabajo, para conocer cómo eran los tipos de preguntas que serián hechas en entrevistas e identificar las carencias de nuestro repertorio lingüístico para expresar nuestras ideas en esa lengua adicional/extranjera.

En el caso de las universidades, participé de varios vestibulares, todos en lengua portuguesa. De esa forma, me enteraba de las epistemologías y metodologías con que los testes eran aplicados; entendía como las respuestas podían ser respondidas; conocía las experiencias de otras personas y el modo con el que utilizaban las bibliografías sugeridas por el edital para el desarrollo de los testes.

Para el escenario migratorio retratado en este artículo, es importante señalar, también, una característica de las personas que dominan más de un idioma, "[...] los translingües tienen habilidad para conectar diversos recursos semióticos para construir sentido y tener éxito en la comunicación." (CANAGARAJAH, 2013, p. 174). ${ }^{28}$ Tal vez, esa condición les permiten ser personas mentalmente más abiertas a los cambios y se les haga más fácil adaptarse a nuevas circunstancias sea cual sea su nivel de dificultad.

En mi condición de mujer (inmigrante) con tres hijas, vivencié situaciones donde me relacioné con personas que mantenían pensamientos patriarcales. Manifestaban su oposición a que, por ser mujer inmigrante, quisiera estudiar o trabajar teniendo hijas y no dominando la lengua portuguesa "perfectamente"; A pesar de observar esa resistencia de parte

\footnotetext{
28 En el original: "[...] translinguals have the ability to align diverse semiotic resources to create meaning and achieve communicative success when words in isolation are inadequate and homogeneous norms are not available in contact zones." Traducción nuestra.
} 
de las personas de algunas instituciones, no desistí de seguir intentando.

Con eso, no solo pretendo hablar de los argumentos o barreras superadas, sino mostrar lo esencial que es mantener un pensamiento de (auto)crítica cuando se está aprendiendo una lengua adicional/extranjera. En esos casos, no es una de las alternativas para vivir en ese nuevo lugar: es la única que le permitirá poder establecerse o permanecer con una calidad de vida.

La palabra critica entra en ese discurso para significar algo diferente de lo que normalmente entendemos por pensamiento crítico (JANKS, 2010, p. 12-13). Aquí, no me refiero solo a un análisis fundamentado en un examen de evidencias o argumentos de resultados correctos o incorrectos. Aquí, se utiliza para señalar lo que está en juego tanto en el plano textual como en lo social, asumiendo sus problemáticas.

Para Janks (2010, p. 23-26), existen varios conceptos que son necesarios entender para que la práctica resulte favorable. Explicaré cada uno de ellos a continuación:

Primero, la dominação: “[...] usada para entender cómo el lenguaje funciona para posicionar los lectores en el interés de poder." (JANKS, 2010, p. 23-26), ${ }^{29}$ una de las situaciones más complicadas cuando uno deja su país y se atreve a comenzar de cero, es estar consciente que, muchas veces, le tocará aceptar situaciones donde tienes que experimentar sentimientos de inferioridad o de exclusión. Quizás, puede tener poca credibilidad que el lenguaje forma parte esencial de nuestra identidad. Cuando socialmente nos toca mantener una posición diferente a la que teníamos antes de emigrar, es necesaria mucha fuerza

29 En el original: "[...] usada para entender como a linguagem funciona para posicionar os leitores no interesse de poder." Traducción nuestra. 
Contribución para la autonomía en el aprendizaje del portugués como lengua de "acogimiento": la historia de una mujer inmigrante venezolana

mental para evitar procesos de depresión o de baja autoestima.

El siguiente es el acesso: se refiere a ofrecer a las personas marginalizadas o con pocos recursos para tener contacto con géneros, letramentos y variedades lingüísticas dominantes. Esa, para mí, fue una de las más complicadas de superar. Algunas veces, he sido confrontada por profesores que no me dejaban utilizar referencias o libros que yo había estudiado en lengua española. En varias oportunidades, para entender los textos en lengua portuguesa, tenía que acudir al traductor de Google. Lo primero que tenemos que hacer es buscar la manera de tener las herramientas básicas para poder actuar.

La diversidade: otro concepto para análisis de esta autora, pues " $[\ldots]$ tenemos que respetar y acomodar los propios conocimientos, prácticas e investimentos de identidad de las personas." (JANKS, 2010, p. 99). ${ }^{30}$ Ello quiere decir que, cuando decidimos participar de alguna actividad social, debemos estar preparados para encontrarnos con diferentes formas de ser, diversas formas de pensar, sentir y hacer (WALSH, 2018), sobre todo con asuntos referidos al país de dónde venimos y oír comentarios que no siempre son agradables. Si estamos conscientes de ese tipo de situaciones, permitiremos que se disminuya el uso de las imposiciones por ambas partes.

Como último asunto, hablare del design: "[...] donde las prácticas multilingües son permitidas en el salón, usando los idiomas de los alumnos para explicar un concepto difícil, los alumnos pueden ser encorajados a usar sus propias lenguas." (JANKS, 2010, p. 114). ${ }^{31}$ En ese punto, enfatizaré la importancia

\footnotetext{
30 En el original: "[...] we do have to respect and accommodate people's own knowledges, practices, and identity investments." Traducción nuestra.

31 En el original: “[ $\ldots$.. where multilingual practices are allowed in class, the teacher might use students' languages to explain a difficult concept, or allow one of the students to do so; students might be encouraged to use their own languages when working in groups." Traducción nuestra.
} 
que puede tener no solo en una escuela o universidad las practicas multilingües, sino, incluso, en cualquier lugar donde se encuentre un inmigrante. Por ejemplo, tener dominio de la lengua de los inmigrantes venezolanos (español), permitiría que, en el área de salud, existiera un mejor atendimiento; en el trabajo, el inmigrante realizaría su acción con un mejor desempeño; en la universidad, las oportunidades de intercambio cultural serian mayores.

Alineada a esa posición, del mismo modo, Janks (2010) destaca algunos aspectos sobre las " [...] formas de dominación y subordinación basadas en formaciones sociales como género, raza, etnía, sexualidad." (JANKS, 2010, p. 35). Lo que nos hace pensar en que las mujeres tenemos una seria de factores que nos limitan a diferencia de los hombres.

Es por eso que pretendo proponer espacios para la ecología de saberes, la cual consisten en:

Garantizar igualdad de oportunidades a diferentes conocimientos en contentas epistemológicas cada vez más amplias con el objetivo de maximizar la contribución de cada uno de ellos en la construcción de una sociedad más democrática, justa y participativa. (SOUSA SANTOS, 2010, p. 19 apud MENESES; BIDASECA, 2018). ${ }^{32}$

Existen algunas formas eurocéntricas dominantes que ese mismo comenta y pueden ser de ayuda para permitir que el lector tenga una mayor comprensión de lo que se espera con este artículo, es decir, entender la importancia de la autonomía del inmigrante. Debido a que, la mayoría de las veces, se conduce el conocimiento de una única forma científica, sin evaluar las

\footnotetext{
32 En el original: "Garantir igualdade de oportunidades a diferentes conhecimentos em disputas epistemológicas cada vez mais amplas com o objetivo de maximizar o contributo de cada um deles na construção de uma sociedade mais democrática, justa e participativa." Traducción nuestra.
} 
Contribución para la autonomía en el aprendizaje del portugués como lengua de "acogimiento": la historia de una mujer inmigrante venezolana

diversas situaciones o condiciones de vida de los diferentes grupos sociales y se lo define como "[...] la monocultura del saber y del rigor del saber." (SOUSA SANTOS, 2010, p. 22), ${ }^{33}$ el aceptar otras formas de conocimiento no solo la ministrada por universidades o escuelas, flexibilizaría los aprendizajes de la nueva cultura. Entiendo que eso explica y expande sobremanera el concepto de lengua de "acogimiento".

En ese mismo sentido, es, aun, esencial mencionar que existe la "monocultura de produtividad capitalista" (SOUSA SANTOS, 2010, p. 22) $)^{34}$ a la cual se aplica al crecimiento económico y a lo que hacemos como ciudadanos o ciudadanas. Todo está relacionado con ese objetivo, sobre todo en los casos de los inmigrantes que llegan al país comenzando con bases muy inestables y de condiciones de vida muy vulnerables.

Se debe considerar la pluralidad siempre que se esté tratando de la enseñanza de lenguas, conforme acentué anteriormente. Eso circunscribe la oportunidad de abrir espacios para otros aspectos en el aprendizaje del portugués para inmigrantes, no solo lo económico, sino, también, aquellos que ayuden a fortalecer a las personas como seres humanos, que necesitan de internamente sentirse satisfechos y respetados. Identificando de manera crítica, las estrategias que amplían las capacidades y autonomía de esas personas pueden ser parte de una transformación social y no solamente un asunto de ayuda humanitaria.

\section{Consideraciones finales}

En este artículo, yo mostré mi lócus de enunciación (BHABHA, 1998), de manera objetiva, al hablar sobre mis

\footnotetext{
33 En el original: "monocultura de produtividade capitalista do saber e do rigor do saber". Traducción nuestra. Basado en criterios únicos de verdad y calidad estética.

34 En el original: "monocultura de produtividade capitalista". Traducción nuestra.
} 
experiencias de aprendizaje de portugués como lengua adicional/ extranjera y al expandir el concepto de lengua de "acogimiento". Abordé situaciones que he vivenciado en Dourados por cinco años realzando mi creatividad para generar espacios de aprendizaje fuera de contextos de instrucción formal. Destaqué situaciones ilustrativas de cómo fue mi proceso de aprendizaje de la lengua portuguesa, los cuales me permitieron probar que las prácticas de lenguaje en la cotidianidad hacen posible el dominio de cualquier lengua adicional sin necesidad de dejar de practicar otra, conforme puntúa Pennycook.

En lo que se refiere al translinguagem, señalé sus principales características y relaté situaciones en que usé las convivencias y como las diferentes formas de coconstrucción de conocimiento auxiliaron al desarrollo de las actividades que realicé y realizo como mujer inmigrante, conforme argumenta (YIP; GARCIA, 2018, p. 170; CANAGARAJAH, 2013, p. 174, entre otros).

Comoreflexión final sobre este tema, dentro del contexto aquí propuesto, puntúo la importancia de la actuación del inmigrante para que cambie su realidad. No basta el acogimiento de quienes le enseñan la lengua portuguesa (lengua de acogimiento) para su adaptación e inclusión social; se hace necesario dedicación y esfuerzo para que se incluya en la sociedad en la que eligió vivir.

De este modo, es una necesidad que sean conocidas otras iniciativas con estrategias de aprendizaje de una lengua adicional/ extranjera, donde la cotidianidad y las relaciones con personas en contextos informales sean la base del conocimiento.

Es de esa manera que un inmigrante también puede convertirse en un ciudadano que, con autonomía y construcción de significados por él mismo, logre insertarse en el proceso social, educativo o laboral, utilizando diversas formas de construcción 
Contribución para la autonomía en el aprendizaje del portugués como lengua de "acogimiento": la historia de una mujer inmigrante venezolana

de sentido, realzando como base las prácticas sociales (JANKS, 2010) sin importar el contexto en que se encuentre.

Como investigadora-profesora, les propongo a las universidades u organismo del estado, considerar esas estrategias de conocimiento que pueden, inclusive, ayudar en situaciones de "acogimiento" a los inmigrantes. Siendo la educación considerada como un motor de cambios, es fundamental entender que, realizando análisis (auto)críticos, que involucran discusiones teóricas y que respondan preguntas sobre situaciones emergentes en la sociedad, puede generar la autonomía en los procesos de adaptación de esos grupos. Espero contribuir, con este artículo, no solo con mis coterráneos, sino también con Brasil y todo país que abrió sus puertas para los venezolanos (y otros inmigrantes), dándoles la oportunidad para recomenzar.

\section{Referencias}

AGENCIA DE LOS ESTADOS UNIDOS PARA EL DESARROLLO INTERNACIONAL (USAID); BANCO INTERAMERICANO DEDESARROLLO (BID).

JuntosEsMejorChallenge. Disponible en: $<\mathrm{https}$ ://www.usaid. gov/JuntosEsMejorVE>. Acceso en: 01 jun. 2020.

\section{ALTO COMISSARIADO DAS NAÇÕES UNIDAS PARA} OS REFUGIADOS (ACNUR). Com apoio da ONU 100 venezuelanos viajam de Boa Vista a Dourados neste sábado. Nações Unidas, 01 fev. 2019. Disponible en: <https:// nacoesunidas.org/com-apoio-da-onu-100-venezuelanos-viajamde-boa-vista-dourados-neste-sabado/>. Acceso en: 10 ago. 2020. ARAÚJO, V. Imigração venezuelana revela um Brasil “de costas" para a América Latina. Jornal Dourados News, Dourados, 14 ago. 2019. Disponible en: <https://www.douradosnews.com.br/ 
dourados/imigracao-venezuelana-revela-um-brasil-de-costaspara-a-america/1110157/>. Acceso en: 20 sep. 2020.

BHABHA, H. K. Thelocationof Culture. London and New York: Routledge, 1994.

BAENINGER, R. (coord.). Migrações Venezuelanas. Campinas, SP: Núcleo de estudos de População "Elza Berquó" - Nepo/Unicamp, 2018.

CANAGARAJAH, S. Translingual Practice: Global Englishes and Cosmopolitan Relations. London, New York: Routledge, 2013.

CANAGARAJAH, S. Translingual Practices and Neoliberal Policies. Attitudes and Strategies of African Skilled Migrants in Anglophone Workplaces, 2017.

CARACTERIZACIÓN demográfica de la población migrante venezolana en Colombia. Observatorio Proyecto Migración Venezuela. 22 abr. 2020. Disponible en: $<$ https://migravenezuela. $\mathrm{com} / \mathrm{web} / \mathrm{articulo} / \mathrm{cuantos}-\mathrm{son}-\mathrm{y}$-donde-estan-losvenezolanosen-colombia-/1636>. Acceso en: 15 ago. 2020.

FREIRE, P. Carta de Paulo Freire aos professores. Ensinar, aprender: leitura do mundo, leitura da palavra. Estudos Avançados, São Paulo, v. 15, n. 42, maio-ago. 2001.

FREIRE, P. Pedagogia do Oprimido.17. ed. Rio de Janeiro: Paz e Terra, 1987.

GARCIA, O. Bilingual Education in the 21st Century: A Global Perspective. Malden, MA and Oxford: Basil/Blackwell, 2009.

IMIGRAÇÃO VENEZUELANA. El progresso, Edición especial, p. 20, 19/20. Dic.2019.

JANKS, H. Literacy and power. New York: Routledge, 2010.

LANKSHEAR, C. A new literacies sampler. New literacies and digital epistemologies, New York, Washington, v. 29, 2007. 
Contribución para la autonomía en el aprendizaje del portugués como lengua de "acogimiento": la historia de una mujer inmigrante venezolana

LANKSHEAR, C.; KNOBEL, M. New Literacies: Everyday practices and classroom learning. 2. ed. Glasglow: McGrawHill, Open University Press, 2006.

LUKE, A. Critical literacy: Foundational notes. Theory into practice, v. 51, n. 1, p. 04-11, 2012.

MONTE MÓR, W.; MORGAN, B. Between conformity and critique.Teaching volunteerism, "activism" and active citizenship: Dangerous pedagogies? Interfaces Brasil-Canadá, Canoas, ed. 14, v. 2, p. 16-35, 2014.

MORANDI, M. Dourados cria força tarefa para atendimento de imigrantes. Jornal Midiamax, 25 jul. 2020. Disponible en: $<$ https://www.midiamax.com.br/cotidiano/2020/dourados-criaforca-tarefa-para-atendimento-de-imigrantes $>$. Acceso en: 05 ago. 2020.

NUNES, Cristina. Venezuelanos colocam Dourados em destaque no ranking de imigrantes. O progresso, Dourados, n. 84, ed. especial, p. 19, 19/20 dez. 2019a. Disponível em: https://issuu. com/progresso/docs/13607. Acceso en: 03 fev. 2020.

ONU. Com apoio da ONU, 100 venezuelanos viajam de Boa Vista a Dourados neste sábado. 2 fev. 2019. Disponible en: <https://www.unodc.org/lpo-brazil/pt/frontpage/2019/02/ com-apoio-da-onu--100-venezuelanos-viajam-de-boa-vista-adourados-neste-sbado-2.html >. Acceso en: 10 ago. 2020.

PENNYCOOK, A. Global Englishes and transcultural flows. London/New York: Routledge. 2007.

PENNYCOOK, A. The Concept of Method Interested Knowledge, and the Politics of Language Teaching. Tesol. Quarterly, v. 23, n. 4, dic. 1989.

RAJAGOPALAN, K. A construção de identidades: linguística e a política de representação. In: RAJAGOPALAN, K. Por uma linguística crítica: linguagem, identidade e a questão ética. São Paulo: Parábola Editorial, 2008. p. 71-76. 
RAJAGOPALAN, K. Por uma linguística crítica: ética linguagem, identidade e a questão ética. São Paulo: Parábola Editorial, 2003.

ROMÃO, J. E.; GADOTTI, M. Paulo Freire e Amílcar Cabral: a descolonização das mentes. São Paulo: Editora e Livraria Instituto Paulo Freire, 2012. Disponible en: $<$ http://projetos. paulofreire.org:8080/jspui/bitstream/7891/508/3/FIPF_2012_ EDL_01_003.pdf>. Acceso en: 03 fev. 2020.

SOUSA, L. T. M. de. Cultura, língua e emergência dialógica. Letras \& Letras, Uberlândia, v. 26, n. 2, p. 296, jul./dez., 2010.

SOUSA, L. T. M. Epistemologías del Sur. In: MENESES; BIDASECA (org.). Epistemologías del Sur - Epistemologias do Sul. Ciudad Autónoma de Buenos Aires: CLACSO; Coímbra: Centro de EstudosSociais - CES, 2018.

STREET, B. Letramentos sociais: abordagens críticas do letramento no desenvolvimento, na etnografia e na educação. Tradução de Marcos Bagno. São Paulo: Parábola, 2014.

TAKAKI, N. H. Futebol, linguagens e sociedade. In: TAKAKI, N. H.; MACIEL, R. F. (org.). Letramentos em terra de Paulo Freire.Campinas, SP: Pontes Editores, 2014.

WALSH, C. Interculturality and decoloniality. In: MIGNOLO, W. D.; WALSH, C. On decoloniality. Concepts. Analytics. Praxis. Durham, London: Duke University Press, 2018. p. 35780.

WEI, L. Translanguaging as a Practical Theory of Language. Applied Linguistics, Reino Unido, Oxford University Press, v. 39, p. 9-30, feb. 2018.

YIP; GARCIA. Translinguagens: recomendações para educadores. Iberoamerica Social: revista-red de estúdios sociales IX, p. 164-177, 2018. 